Academic Platform Journal of Engineering and Science

journal homepage: http://apjes.com/

\title{
Soya Yağı ile Kömür Yıkama Tesis Atıklarından Temiz Yakıt Üretimi
}

\author{
${ }^{* 1}$ Hasan Hacıfazlıoğlu, ${ }^{2}$ Yakup Eker, ${ }^{3}$ Abdul Vahap Korkmaz \\ * ${ }^{1}$ İstanbul Üniversitesi-Cerrahpaşa, Mühendislik Fak., Maden Müh. Böl., hasanh @istanbul.edu.tr, \\ ${ }^{2}$ Gebze Teknik Üniversitesi, Kimya Bölümü, Kocaeli., yakupeker78@hotmail.com (DD \\ ${ }^{3}$ İstanbul Üniversitesi-Cerrahpaşa, Mühendislik Fak., Maden Müh. Böl., av.korkmaz06@gmail.com,
}

Araștırma Makalesi

Geliș Tarihi: 27.06.2018

Kabul Tarihi: 17.10.2018

\section{$\ddot{\mathbf{O} z}$}

$\mathrm{Bu}$ çalışmada agloflotasyon deneyleri yapılmış ve Zonguldak’ta faaliyet gösteren bir kömür yıkama tesisinin ince $(<500 \mu \mathrm{m})$ atıkları kullanılmıştır. \%33.75 küllü atıklar soya yağı ile karıştırılıp aglomere edildikten sonra bir flotasyon hücresine alınmış ve bu hücre içinde temiz kömür/yakıt yüzdürülerek ayrılmıştır. Yüzen temiz kömürlerin ağırlıça verimi \%56.40 olup, kül içeriği \%14.80 bulunmuştur. Net kalorifik değer 3620'den 5072 kcal/kg'a yükseltilmiştir. Ayrıca, fosil bir yakıt olan ve flotasyonda yaygın olarak kullanılan gazyağı ile de testler yapılmış ve sonuçlar soya yağının sonuçları ile karşılaştırılmıştır. Bir kollektör olarak soya yağı verimlilik ve seçimlilik yönünden gazyağına göre yaklaşık \%20 daha düşük performans göstermiştir.

Anahtar Kelimeler: Aglomerasyon, Agloflotasyon, Atık Kömür, Flotasyon, Soya Yağı

\section{Clean Fuel Production from Coal Washery Plant Wastes vith Soybean Oil}

\author{
*1 Hasan Hacıfazlıoğlu, ${ }^{2}$ Yakup Eker, ${ }^{3}$ Abdul Vahap Korkmaz \\ ${ }^{*}$ Istanbul University-Cerrahpasa, Engineering Faculty, Mining Engineering Department, Istanbul. hasanh@istanbul.edu.tr \\ ${ }^{2}$ Gebze Tecnical University, chemistry department, Kocaeli. Yakupeker78@ hotmail.com \\ ${ }^{3}$ Istanbul University-Cerrahpaşa, Engineering Faculty, Mining Engineering Department, İstanbul. av.korkmaz06@gmail.com
}

\begin{abstract}
In this study, agloflotation experiments were conducted and fine $(<500 \mu \mathrm{m})$ wastes from a coal washing plant operating in Zonguldak were used. $33.75 \%$ ash wastes were mixed with soybean oil and agglomerated, then taken to a flotation cell and clean coal/fuel was floated in this cell. The yield of the floating clean coal was $56.40 \%$ by weight and the content of ash was $14.80 \%$. The net calorific value was increased from 3620 to $5072 \mathrm{kcal} / \mathrm{kg}$. In addition, tests were conducted with kerosene, a fossil fuel and widely used in flotation, and the results were compared with those of soybean oil. Soybean oil as a collector showed about $20 \%$ lower performance than the kerosene in terms of efficiency and selectivity.
\end{abstract}

Keywords: Aglomeration, Agloflotation, Waste Coal, Flotation, Soybean Oil, Waste

\section{GíRiş}

Kömür madenciliği ve kömürün hazırlanması esnasında yüksek miktarlarda ince boyutlu toz kömür ortaya çıkmaktadır. Özellikle Zonguldak havzasında üretilen kömürlerin çok kırılgan olması nedeniyle toplam üretimin $\% 15-20$ 'si toz $(<0.5 \mathrm{~mm})$ kömürlerden oluşmaktadır. Toz kömürlerin zenginleştirilmesi maliyetli ve düşük verimli bir işlemdir. $\mathrm{Bu}$ bakımdan kömür işletmecileri genellikle toz kömürü zenginleştirmeden düşük kalorifik değerli olarak satma yoluna giderler. Bu durum, başta çevre sorunları olmak üzere işletmeciler için çeşitli ekonomik kayıplara da neden olur. Ayrıca, yüksek küllü toz kömürün pazarı kısıtlı olup, bu kömürler atık havuzlarında ya da atık sahalarında yıllarca bekleyebilmektedir. Günümüzde yüksek kül içerikli toz kömürlerin değerlendirilmesi ülke ekonomisi ve gelecekteki enerji hammadde gereksinimleri açısından zorunluluk haline gelmiştir. Önceleri herhangi bir temizleme işlemine girmeden, doğrudan tuğla, çimento gibi sanayi tesislerinde ya da termik santrallerde yakılan toz kömürler, günümüzde çeşitli temizleme işlemlerinden geçirilerek demir-çelik sanayisi gibi yüksek kalorifik değer gerektiren çeşitli alanlarında kullanılabilmektedir. Kömürün kalorifik değeri arttıkça, kömür daha temiz bir yakıt haline gelmekte 
ve pazarı genişleyerek satış fiyatı da o derece yükselmektedir. Literatürden de bilindiği gibi, ortalama kül içeriği \%50 olan Zonguldak havzasında üretilen tüvenan toz kömürlerden flotasyon yöntemi ile \%6-12 küllü temiz kömürler üretilebilmektedir [1, 2]. Bu çalışmada daha yüksek miktarlarda bağlayıcı yağ (soya yağı) kullanılacağı için agloflotasyon yönteminin flotasyona göre daha başarılı olacağı tahmin edilmektedir.

Flotasyon ya da agloflotasyon işleminin verimini etkileyen en önemli işlem parametresi toplayıcı (bağlayıcı) tipi ve miktarıdır. Toplayıcının uygun seçilememesi ve miktarının uygun olmaması durumunda flotasyon verimi önemli ölçüde düşer. Toplayıcılar hidrokarbon zinciri içeren iyonlaşan ve iyonlaşmayan organik bileşiklerdir. İyonlaşan toplayıcılar polar ve apolar gruplardan oluşur. Bu toplayıcılar polar ucu mineral yüzeyine yapışarak minerale hidrofilik özellik kazandırır. Suda çözünmeyen emülsiyon olarak kullanılan ve mineral yüzeyini kaplayarak o yüzeyi hidrofob hale getiren hidrokarbon yağlardan ibaret bileşikler iyonlaşmayan toplayıcılardır. Bunların en önemlileri kömür flotasyonunda da yaygın olarak kullanılan gazyağı, dizel, fuel oil gibi petrol ürünleri ve henüz endüstriyel ölçekte kullanımı bulunmayan doğal bitkisel yağlardır [3-5].

Ülkemizde endüstriyel ölçekte kömüre flotasyon nadiren uygulanmaktadır. Bunun en önemli nedeni; petrol fiyatlarının yüksek olması ve yüksek miktarlarda $(0.5-1 \mathrm{~kg} / \mathrm{t})$ petrol ürünlerinin (gazyağı, dizel vb.) kullanılmasıdır. Oysa, pek çok ülkede özellikle toz kömürlerin zenginleştirilmesi için flotasyon yöntemi yaygın olarak kullanılır. Çünkü çok ince boyutlu taneleri flotasyona göre daha ekonomik olan klasik gravite yöntemleri (spiraller, masalar gibi) ile zenginleştirmek mümkün değildir. Türkiye'de yılda ortalama 70 milyon ton düzeyinde kömür üretilmekte ve bunun en az 1 milyon tonu çok ince boyutlu olduğu için -özellikle linyit kömürler- atık barajlarına gönderilmektedir. Taş kömürleri ise hiçbir işleme tabi tutulmadan pazarı bulunursa doğrudan termik santral yakıtı olarak değerlendirilmektedir. Ekonomik bir flotasyon yönteminin bulunması durumunda bu kömürlerin kalorifik değeri arttırılabilir ve daha temiz yakıtlara dönüştürülerek pazarı genişletilebilir. Son yıllarda bitkisel yağların toplayıcı ya da bağlayıcı olarak kullanılmasıyla ilgili pek çok çalışma yapılmıştır. Kömür flotasyonu için petrol ürünlerine alternatif olarak yemeklik bitkisel yağların kullanılabileceği pek çok araştırmacı tarafından belirtilmiştir. Ayrıca, kızartma işlemleri sonucunda oluşan atık bitkisel yağların da agloflotasyonda kullanılabileceği belirtilmektedir [6-11]. Alonso vd. [7] yapmış oldukları bir çalışmada, ham ve rafine bitkisel yağların performansını gazyağı ile karşılaştırmalı olarak ortaya koymuşlardır. Bu çalışmada, gazyağının bitkisel yağlara göre biraz daha verimli olduğu ancak maliyet yönünden bitkisel yağın çok daha avantajlı olduğu belirtilmiştir. Valdes ve Garcia [8] yüksek küllü kömür atıklarına farklı bitkisel atık yağlarla (zeytin yağ $(\mathrm{AB})$ ve $1: 1$ ayçiçek+zeytinyağı(JS)) aglomerasyon uygulamış ve kül gideriminde \%80'lere varan bir başarı sağlamıştır. Aglomerasyonda yağ konsantrasyonu \%5 ile \%50 arasında değiştirilmiş ve yağ konsantrasyonu arttıkça kül giderimi düşmüştür. Organik madde kazanımı ise yağ konsantrasyonuyla birlikte artmıştır. Bitkisel yağların içerisinde uzun zincirli yağ asitleri bulunduğu için bu asitler toplayıcılık yanında köpürtücü görevi de görmüş ve bu yüzden aglomeratlar köpürtücüsüz flotasyon yöntemiyle toplanmıştır. Das ve Reddy [9] Polanga ve Mahua bitkisel yağlarını kömür flotasyonunda kullanmış ve koklaşmayan yüksek küllü kömürün flotasyon yeteneğini arttırmışlardır. Chary ve Distar [11] yağ aglomerasyonunda çeşitli bitkisel yağları (jatropha yağı, karanja yağı, kauçuk tohumu yağı, pamuk tohumu yağı, ayçiçek yağ1, soya yağı, kastor yağı, palmiye yağı, susam ve Hindistan cevizi yağ kömürün temizlenmesi için en uygun olan yağ araştırmışlardır. En yüksek organik madde kazanımı \%94.72 ile karanja yağı ile elde edilmiştir. Verimlilik indeksi değeri yönünden en yüksek değeri $(\% 68,50)$ veren soya yağı olmuştur. Daha sonra sırasıyla en yüksek verimlilik indeksleri karanja (\%52.44) ve susam yağı (\%50.86) ile elde edilmiştir. Hacıfazlıŏlu ve Senol-Arslan [10] kömür flotasyonunda kolektör olarak ayçiçek yağı kullanmış ve sonuçları gazyağı kolektörü ile karşılaştırmıştır. Ayçiçek yağı ve gazyağı için temas açıları sırasıyla 88 ve 100 derece bulunmuştur. Ayçiçek yağının gazyağına alternatif olarak kullanılabileceğini ancak verimlilik yönünden \%20-30 daha düşük performans sağladığını belirtmişlerdir.

Bu çalışmada yapılan agloflotasyon işleminde, petrol ürünü gazyağına alternatif olarak soya yağı bağlayıcı olarak kullanılmıştır. Soya yağının kullanılma nedeni, ülkemizde üretilebiliyor olması, üretim maliyetinin düşük olması ve yapılmış olan çoğu çalışmada yüksek verimlilik sağlamış olmasidir.

\section{MALZEME VE YÖNTEM}

\subsection{Tesis Atığının Özellikleri}

Deneysel çalışmalarda kullanılan atık numunesi, Zonguldak Çatalağzı beldesinde faaliyet gösteren bir kömür yıkama tesisinin atık havuzundan alınmıştır. \%26 nem içeriğine sahip olan numune homojen hale getirildikten sonra konileme-dörtleme ile azaltılarak deneylerde kullanılmıştır. Etüvde $105{ }^{0} \mathrm{C}$ 'de tamamen kurutulmuş numuneye uygulanan kısa kimyasal analiz sonuçları Tablo 1'de verilmiştir. $1 \mathrm{~kg}$ 'lık numuneye uygulanan yaş elek analizi sonucunda, tüm malzemenin 500 mikronun altında olduğu ve ortalama tane boyutunun $\left(\mathrm{d}_{50}\right) 30$ mikron olduğu tespit edilmiştir.

\subsection{Deneylerde İzlenen Yöntem}

Agloflotasyon deneyleri, 2 aşamada gerçekleştirilmiştir. İlk aşamada Daihan marka HS-120A modeli bir karıştırıcı (stirrer) ile 2000 lt'lik bir reaktör içerisinde, 1500 dev/dk'lik bir karıştırma hızında; 330 gr kuru kömür ve 1320 gr musluk suyu kullanılarak \%20 katı oranında aglomerasyon deneyleri yapılmıştır. İkinci aşamada aglomerasyondan elde edilen aglomeratların toplanması için Denver marka flotasyon 
makinesi kullanılmıştır. 10 dakikalık bir aglomerasyon süresi sonunda elde edilen aglomeratlı pülp flotasyon hücresine alınmış ve aglomeratlar köpürtücüsüz olarak 1000 dev/dk'lık karıştırma hızında yüzdürülmüştür. Yukarıdaki prosedür, soya yağı ve gazyağ 1 için ayrı ayrı tekrarlanmıştır. Aglomeratların toplandığı flotasyon hücresi (1) ve elde edilen ürünlerin görüntüleri (2) ve filtrasyonu (3) Şekil 1'de gösterilmiştir.

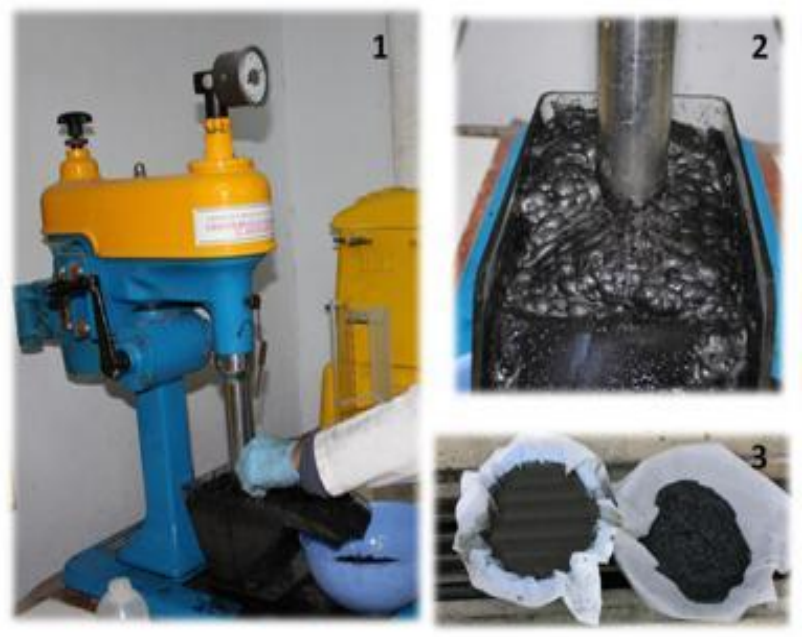

Şekil 1. Agloflotasyon deney düzeneği ve elde edilen ürünlerin görüntüleri [2]

Tablo 1. Kömür Y1kama Tesis Atığı Kısa Kimyasal Analiz Sonuçları

\begin{tabular}{|l|c|}
\hline \multicolumn{1}{|c|}{ Analiz } & Değeri \\
\hline Kül (\%) & 33.75 \\
\hline Uçucu Madde (\%) & 29.20 \\
\hline Sabit Karbon $(\%)$ & 37.50 \\
\hline Toplam Kükürt $(\%)$ & 0.70 \\
\hline Net Kalorifik Değer $(\mathrm{kcal} / \mathrm{kg})$ & 5390 \\
\hline $\mathrm{d}_{50}(\mu \mathrm{m})$ & 30 \\
\hline
\end{tabular}

Deneylerde kullanılan soya yağı, yemeklerde kullanılan ve ortalama fiyatı 1.5 \$ olan yağdır. Fıçılarla alınması durumunda yağın litre fiyatı 1 \$'a kadar düşmektedir. İstanbul'da faaliyet gösteren bir petrol ofisinden temin edilen gazyağının litre fiyatı ise $2 \$$ civarındadır. Yukarıda adı anılan yağlarla yapılan deneylerin agloflotasyon koşulları Tablo 2'de, agloflotasyon anı görüntüleri ise Şekil 2'de gösterilmiştir. Gonyometrede Sessile damla yöntemi ile yapılan temas açısı ölçümlerinde gazyağının temas açısı 100, soya yağınınki 89 derece bulunmuştur.

Soya yağı ve gazyağı ile yapılan farklı yağ dozajlarında elde edilen sonuçların değerlendirilmesi için "yanabilir verim" ve "verimlilik indeksi" formüllerinden faydalanılmıştır. Yanabilir verim ve verimlilik indeksi değerleri aşağıdaki eşitliklerle hesaplanmıştır. $\mathrm{Bu}$ eşitliklerde, $\mathrm{Mt}$ temiz kömürün \% miktarı, $\mathrm{Kt}$ temiz kömürün $\%$ külü, $\mathrm{Mb}$ beslenen kömürün \% miktarı ve $\mathrm{Kb}$ beslenen kömürün $\%$ kül değeridir.
Tablo 2. Agloflotasyon Deney Koşulları

\begin{tabular}{|l|c|}
\hline \multicolumn{1}{|c|}{ Parametre } & Değeri \\
\hline Toplayıc1 & $5,50,100,200,300 \mathrm{~kg} / \mathrm{t}$ \\
\hline Köpürtücü & $0 \mathrm{~g} / \mathrm{t}$ \\
\hline Karıştırma Hızı & $1000 \mathrm{dev} . / \mathrm{dk}$ \\
\hline Katı Oranı & $\% 20$ \\
\hline Pülp Sıcaklığ & $25^{\circ} \mathrm{C}$ \\
\hline
\end{tabular}

YanabilirVerim $(\%)=\frac{M_{t} x\left(100-K_{t}\right)}{M_{b} x\left(100-K_{b}\right)} \times 100$

Verimlilik İndeksi $=$ Yanabilir verim $\mathrm{x}$ Artık külü/Temiz kömür külü
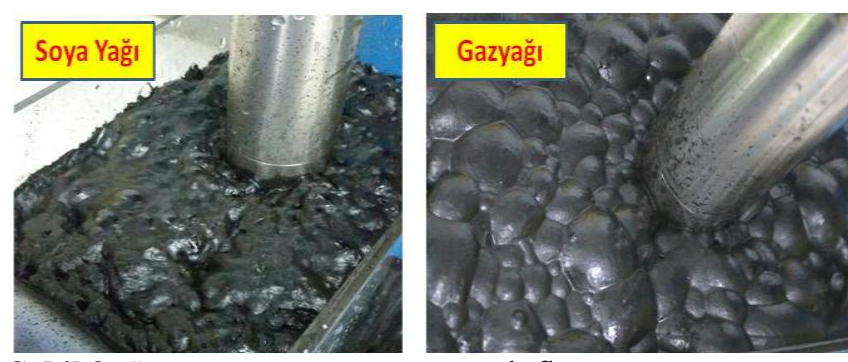

Şekil 2. Soya yağı ve gazyağının agloflotasyon anı görüntüleri

\section{BULGULAR}

$5,50,100,200$ ve $300 \mathrm{~kg} / \mathrm{t}$ yağ miktarlarında ayrı ayrı soya yağı ve gazyağı ile yapılmış olan agloflotasyon çalışmaları sonucunda elde edilen ürünlerin kül, yanabilir verim ve verimlilik indeksi değerleri karşılaştırmalı olarak Şekil 35'de gösterilmiştir. Şekil 6'da soya yaği ile üretilen temiz kömür ve elde edilen atığın görüntüleri verilmiştir.

Şekil 3-5'deki verilere göre; en düşük yağ miktarında (5 $\mathrm{kg} / \mathrm{t}$ ); soya yağının ürettiği temiz kömürün külü \%12.50, ağırlıça verimi \%8.70 bulunmuştur. Yanabilir verim ve verimlilik indeks değerleri ise sırasıyla \%10.83 ve 30.91 'dir. Aynı yağ miktarında gazyağının ürettiği temiz kömürün külü $\% 12.00$, ağırlıkça verimi \%10.50 bulunmuştur.

Yanabilir verim ve verimlilik indeks değerleri ise sırasıyla $\% 13.95$ ve 42.19 'dur. Optimum yağ miktarında (200 kg/t) ya da yüksek yă miktarlarında $(300 \mathrm{~kg} / \mathrm{t})$, soya yağının agloflotasyondaki performansı gazyağı ile yaklaşık olarak aynıdır. Soya yağı gazyağına göre \%10-\%13'lük daha düşük bir verimlilik indeksi değeri vermiştir. Bunun nedeni, soya yağının yapısında bulunan oksijen guruplarıdır [10].

Gazyağı toplayıcısı özellikle düşük konsantrasyonlarda daha verimli iken, soya yağı yüksek konsantrasyonlarda daha iyi sonuçlar vermiştir. Agloflotasyonda soya yağının yüksek konsantrasyonlarda daha yüksek verim sağladığı söylenebilir. 


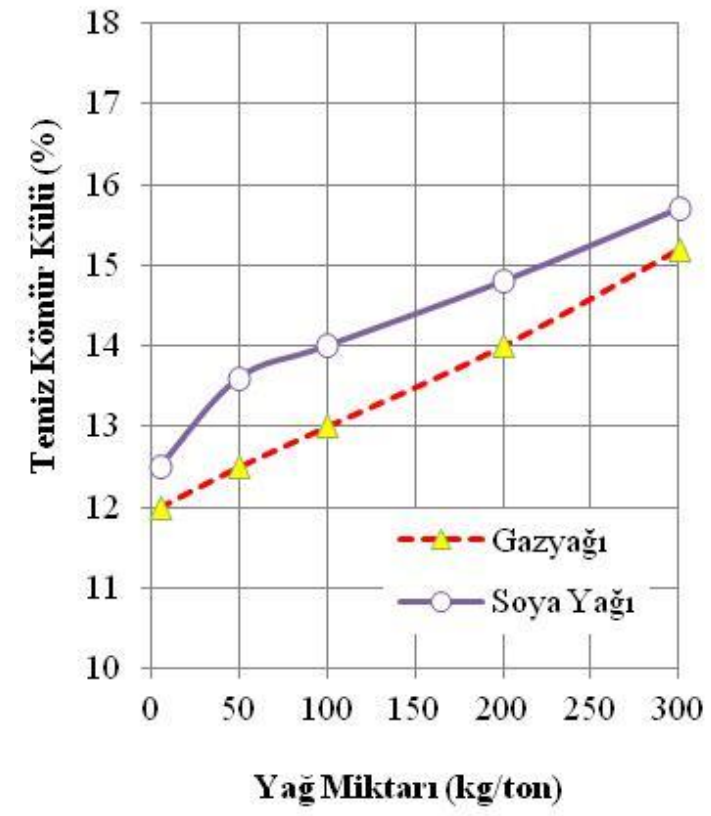

Şekil 3. Yağ miktarına bağlı olarak elde edilen temiz kömürlerin kül değerleri

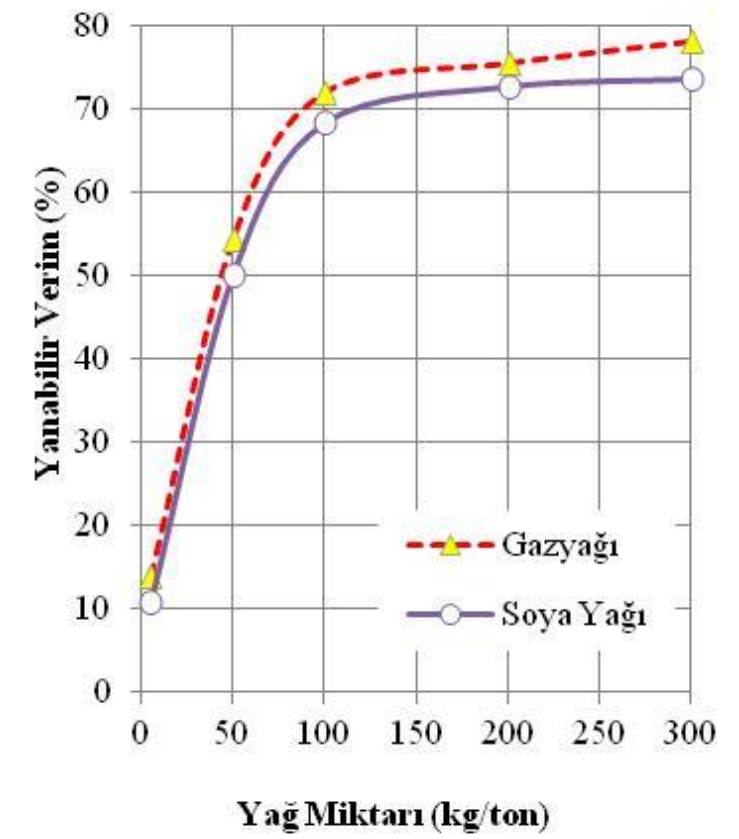

Şekil 4. Yağ miktarına bağlı olarak elde edilen yanabilir verim değerleri

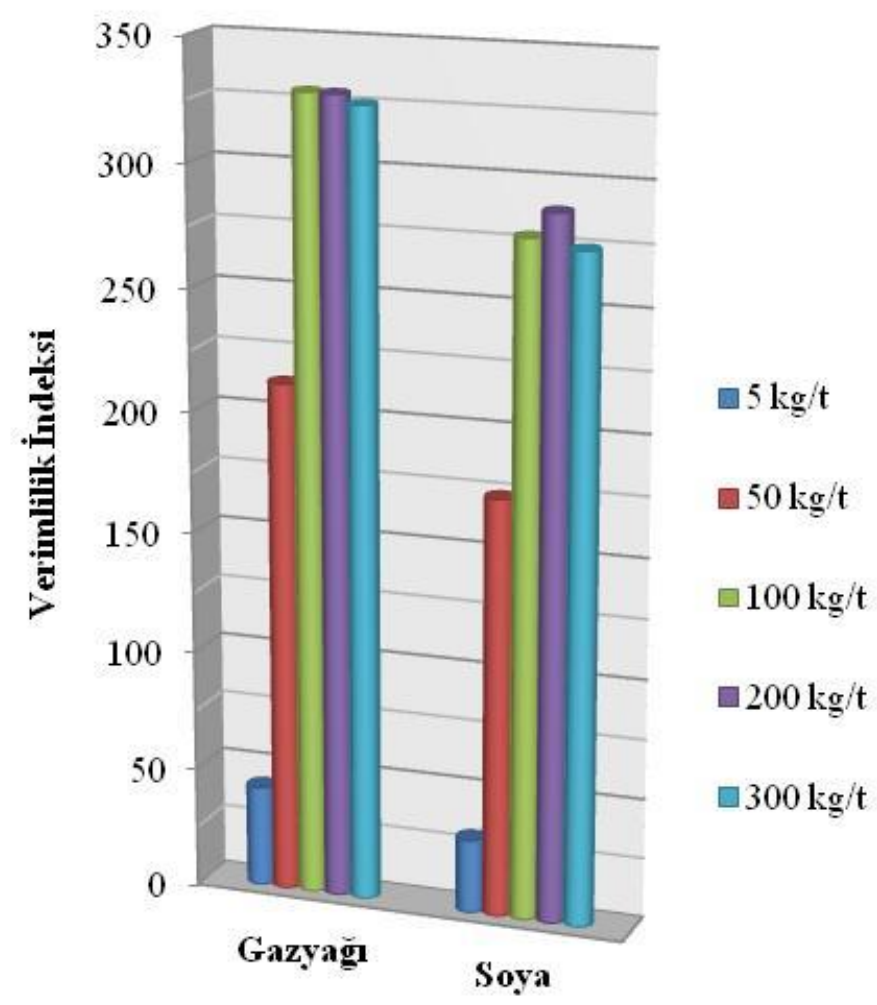

Şekil 5. Yağ miktarına bağlı olarak verimlilik indeksi değerleri

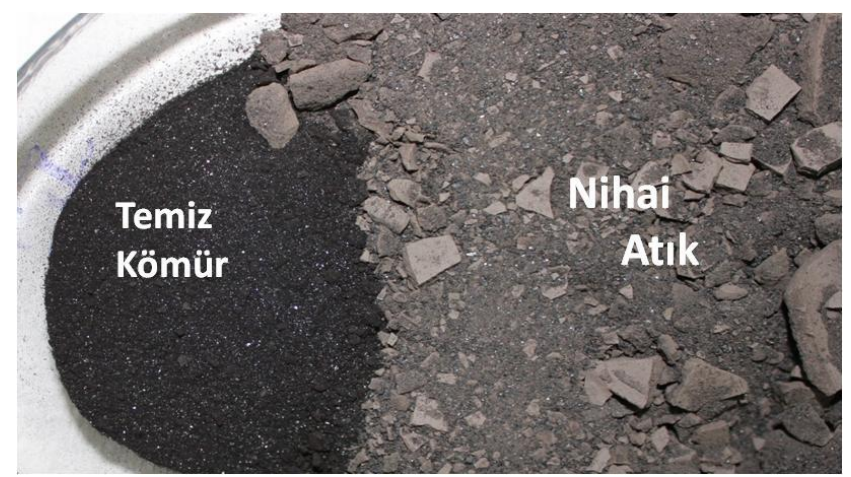

Şekil 6. Soya yağı ile atık kömürden üretilen temiz kömür ve nihai atığın görüntüsü

\section{TARTIŞMA VE SONUÇ}

Tesis atıklarından flotasyon veya agloflotasyon yolu ile temiz kömür üretiminde gazyağı, dizel, fuel oil gibi genellikle petrol türevi reaktifler kullanılmaktadır. $\mathrm{Bu}$ reaktifler maliyetli, tükenebilir ve çevre dostu olmayan reaktiflerdir. Ayrıca petrol ürünleri yenilenemez olup, yakın gelecekte de tükenecektir. Bu çalışmada, agloflotasyonda toplayıcı olarak bitkisel soya yağı kullanılmıştır. Soya yağı ve gazyağı ile ayrı ayrı agloflotasyon çalışmaları yapılmış ve elde edilen sonuçlar kül, yanabilir verim ve verimlilik indeksi bakımından karşılaştırılmıştır. Deneylerde köpürtücü kullanılmamıştır. Sonuçlar göstermiştir ki; soya yağı temiz kömür üretebilme kapasitesi bakımından gazyağına alternatif olarak kullanılabilecek bir yağdır. Öyle 
ki; \%33.75 küllü tesis atıklarından \%12-\%16 küllü temiz kömürler üretebilmektedir. Üretilen bu temiz kömürlerin alt kalorifik değerleri 5000-6000 kcal/kg civarındadır. Ancak soya yağı verimlilik ve seçimlilik yönünden gazyağına göre yaklaşık \%20 daha düşük performans göstermiştir. Fosil kaynakların hızla tükendiği günümüzde, soya yağının yenilenebilir ve düşük maliyetli olması önemli bir avantajdır. Ancak buradaki en önemli maliyet unsuru yüksek miktarlarda yă̆ kullanılmasıdır. Yağın geri kazanılmasının mümkün olduğu durumda soya yağı ile agloflotasyon yöntemi ekonomik olabilir. $\mathrm{Bu}$ bağlamda, yağın geri kazanımına yönelik çalışmaların yürütülmesi veya atık bitkisel yağlarla çalışmaların yürütülmesi ekonomik olarak daha yapılabilir gözükmektedir.

\section{TEŞEKKÜR}

Bu çalışmayı, İstanbul Üniversitesi Bilimsel Araştırma Projeleri Birimi 24358 No'lu proje ile desteklemiştir.

\section{KAYNAKÇA}

[1] K. Bilir, "Kömür Flotasyonunda Kullanılan Gazyağı Miktarının Oranların Farkı Testi ile Optimizasyonu", Eskişehir Osmangazi Üniversitesi Mühendislik Mimarlık Fakültesi Dergisi, 24, 1, 119-130, (2011).

[2] H. Hacifazlioğlu and G.H. Gerdan, "Taşkömürü Tozları Flotasyonunda Sıcaklığın Etkisi”, Adıyaman Üniversitesi Mühendislik Bilimleri Dergisi, 5, 1-8, (2016).

[3] S. Bhattacharya and R.D. Pascoe, "Effect of Temperature on Coal Flotation Performance - A Review,
Mineral Processing \& Extractive Metall. Rev., 26, 1, 31-61, (2005).

[4] S.M. Bulatovic, 2007. Handbook of flotation reagents: chemistry, theory and practice: Volume 1: flotation of sulfide ores, Elsevier Science, Peterborough, Ontario, Canada, (2007).

[5] S. Atak and R. Tolun, Cevher Hazırlama El Kitab1, Ed.G.Önal, G.Ateşok, K.T.Perek., YMGV, İstanbul, 185236, (2014).

[6] N. Vasumathi, T.V.J. Kumar, S.S. Rao, S. Parabhakar, G.B. Raju, S.S. Kumar and U. Raman, "Eco Friendly and Cost Effective reagent for coal flotation", International Journal of Engineering Research, 2, 7, 418-423, (2013).

[7] M.I. Alanso, C. Castano and B. Garcia, "Performance of vegetable oils as flotation collectors for the recovery of coal from coal fines wastes", Coal Preparation, 21, 411-420, (2000).

[8] A.F. Valdes and A.B. Garcia, "On the utilization of vaste wegetable oil (WVO) as agglomerants to recover coal from coal fines cleaning wastes (CFCW)", Fuel, 85, 607-614, (2006).

[9] B. Das and P. Reddy, "The utilization of non-coking coal by flotation using non-conventional reagents" Energy Sources, Part A: Recovery, Utilization, and Environmental Effects, 32(19), 1784-1793, (2010).

[10] H. Hacifazlioglu and D. Senol-Arslan, "Sunflower oil as green collector in bituminous coal flotation", Energy Sources, Part A: Recovery, Utilization, and Environmental Effects, 39:15, 1602-1609 (2017).

[11] G.H.V.C. Chary and M.G. Dastidar, "Comprehensive study of process parameters affecting oil agglomeration using vegetable oils", Fuel, 106, 285-292, (2013). 